\title{
Low Head Pico Hydro Turbine Selection using a Multi-Criteria Analysis
}

\author{
S.J. Williamson*, B.H. Stark, J.D. Booker \\ Faculty of Engineering, University of Bristol, Bristol, UK \\ * Corresponding author, Tel: +44 (0)117954 5499,E-mail: sam.williamson@bristol.ac.uk
}

\begin{abstract}
Turbine types suit specific ranges of head, flow rate and shaft speed and are categorised by specific speed. In the pico range, under $5 \mathrm{~kW}$, the requirements are often different to that of larger scale turbines and qualitative requirements become more influential. Pico hydro turbines can be applied beyond these conventional application domains, for example at reduced heads, by using non-traditional components such as low speed generators. This paper describes a method to select which turbine architecture is most appropriate for a low-head pico hydro specification using quantitative and qualitative analyses of 13 turbine system architectures found in literature. Quantitative and qualitative selection criteria are determined from the particular requirements of the end user. The individual scores from this analysis are weighted based on perceived relative importance of each of the criteria against the original specification and selects a turbine variant based on the total weighted score. This methodology is applied to an example of a remote site, low head and variable flow specification and used to select a propeller turbine variant or single-jet Turgo turbine for this specification.
\end{abstract}

Keywords: Pico hydro, Turbine selection, Low head, Application Range, Turgo

\section{Introduction}

Typically, selecting hydro turbines is based on the specific speed of the turbine, a nondimensional parameter that includes head, output power and output shaft speed [1]. From this, the commonly used application domain for turbines is used to aid selection, as in Fig. 1, which has been compiled from [2], [3] and [4]. This leads to the choice of Pelton and Turgo turbines at high heads, crossflow and radial (Francis) turbines at mid heads and propeller turbines and waterwheels at low heads. This is also reflected in the commercially available turbines for these heads.

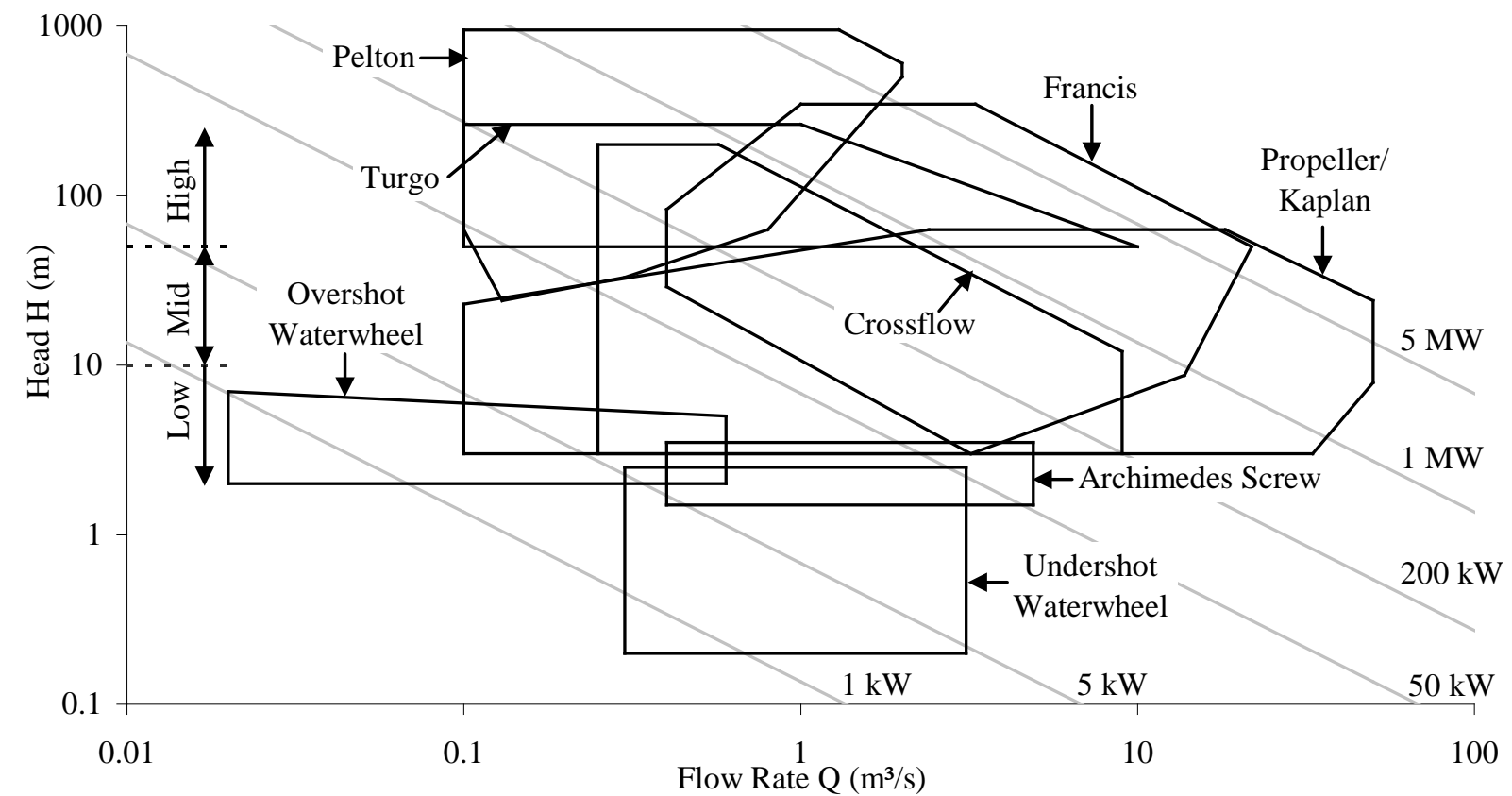

Fig. 1. Turbine application range chart, adapted from data in [2], [3] and [4]. 
As can be seen in Fig. 1, the pico range, under $5 \mathrm{~kW}$ generation, appears to be sparsely covered by reported application domains. There are several commercially available pico hydro products at high, mid and low head, and these tend to follow the topology of the larger scale turbines. The use of traditional 4 or 6-pole generators and direct generator-grid interfaces restricts the application domains for pico hydro turbines. However, introducing technologies such as low speed generators or inverter based grid interfaces generally extends a turbine's application domain, thus providing alternative turbine solutions. In addition, the requirements on a pico hydro turbine tend to be different to those of a larger scale turbine; pico hydro generators cannot carry the cost of unique designs for each location, requiring instead off-the-shelf solutions. It can be located in remote locations, several hours walk from the nearest road and have no skilled labour locally to operate and maintain the system. The application domain selection method of turbine selection does not take these more qualitative factors into account. The method proposed in this paper is used to select a pico hydro turbine for a low head specification using both quantitative and qualitative criteria.

\section{Methodology}

\subsection{Selection Criteria}

Each turbine system will have a set of requirements and specification. This will include either site conditions, such as head and flow rate, or output power requirements. There will be environmental requirements, for example the site may be in an inaccessible location, be subject to extremes in temperature or have to comply with fishery regulations. The turbine may be able to have regular maintenance checks from an onsite operator, or it may be required to be operated remotely and therefore should require minimal maintenance and have a high reliability. Using the requirements, a set of selection criteria can then be developed. Table 3 shows the selection criteria used in the method example in Section 3. Some of the criteria can be assessed through a quantitative analysis, whilst others are less quantifiable, and so will require a qualitative analysis. These analyses are then combined to give each turbine type a final score.

\subsection{Quantitative Analysis}

Basic fluid flow equations are used to derive simple performance characteristics about the turbine option for the quantitative analysis. The performance variables are turbine power $P$, overall turbine system efficiency $\eta$, flow rate $Q$, and gross head $H_{g}$, two of which will need to be defined, leaving two unknowns. These variables are combined using Eq. (1) [1] for a general turbine system.

$P=\eta \rho g Q H_{g}$

where $\rho$ is density and $g$ is the gravitational constant. The two unknowns are solved using a second equation, which is derived from further analysis of the turbine torque generation mechanism. This analysis may result in the power available at a specific site and the turbine system efficiency or the efficiency and flow rate required to produce a specified power depending on the variables defined. There are 13 turbine types commonly used which are divided into 4 categories: Impulse, Reaction, Archimedes Screw, and Waterwheel. Each category has a different torque generation mechanism and is analysed in a different manner, as summarised in the following Sections. The performance modelling used here is simplified, neglecting fluid mechanic non-linearities, and assumes linear geometric scaling. For some turbines considered, impractical geometries are generated at the extremes of their head range. 


\subsubsection{Impulse Type - Pelton and Turgo (single and multiple jet), Crossflow}

Velocity triangles of the water jet impacting with the blade of the turbine are used to analyse the impulse turbines [1]. The head loss in the penstock $H_{l l}$ reduces the inlet jet velocity. The change in whirl velocity $\Delta v_{w}$ is used to calculate the rate of change in momentum of the water, generating a force at the blade. The force is concentrated at the jet impact point, radius $r$, assuming the flow enters and exits at the same radius, which causes a torque $T$ on the wheel. The power is then the product of the rotational speed at maximum power $\omega$ by the torque

$$
P=T \omega=Q \rho \Delta v_{w} r \omega .
$$

\subsubsection{Reaction Type - Axial, Radial}

The gross head $H_{g}$ in Eq. (1) is reduced by head losses in the penstock $H_{l 1}$, the draft tube $H_{l 2}$, and from the outflow kinetic energy $H_{l 3}$. These head losses are functions of the speed of the water passing through the component and a factor dependent on the geometry of the component [1]. The power generated is then dependent on the net head and the estimated turbine hydraulic efficiency $\eta_{t}$, which is different to $\eta$ in Eq. (1),

$$
P=\eta_{t} \rho g Q\left(H_{g}-H_{l 1}-H_{l 2}-H_{l 3}\right) \text {. }
$$

\subsubsection{Archimedes Screw}

The Archimedes screw operates on a hydrostatic pressure difference across the blades [5]. The efficiency $\eta$ is a function of the geometry of the screw $n$, the diameter $D$, and the flow passing through it $Q$

$\eta=\left(\frac{2 n+1}{2 n+2}\right)\left(1-\frac{0.01125 D^{2}}{Q}\right)$.

\subsubsection{Waterwheels - Overshot, Breastshot, Undershot}

The analysis for the waterwheels is based on the losses in the system, as described in [6]. For the Overshot and Breastshot Waterwheels it is assumed that the losses are only the kinetic energy loss from the water entering the wheel $H_{l 4}$, and the swirl in the water on the exit of the wheel $H_{l 5}$, and the efficiency is then

$\eta=\left(\frac{H_{g}-H_{l 4}-H_{l 5}}{H_{g}}\right)$.

For an Undershot Waterwheel, two efficiency losses are considered. First the inlet efficiency $\eta_{\text {th }}$ represents the non-ideal flow entrance due to fixed wheel geometry, second the friction on the water bed $h_{l 6}\left(=H_{l 6} / H_{g}\right)$, which models friction loss as a function of inlet water velocity. The efficiency is then

$\eta=\eta_{t h}-h_{l 6}$. 


\subsection{Qualitative Analysis}

The qualitative analysis uses clearly defined criteria to score the qualitative aspects of the turbine selection, as in [7]. Each criterion is given an unambiguous definition and a defined scoring system between 1 (poor) and 5 (excellent). Each turbine is then scored against this scoring system as a part of a team discussion. An example of the scoring system is shown in Table 1, which was developed as part of the research methodology and used in Section 3.

Table 1. Example qualitative scoring definition and criteria.

\section{Scope for Modularity}

Definition - Modules that allow the system to be broken into carryable/shippable units and allow line replaceable for easy servicing and fault identification, with the ability to interchange identical modules.

\begin{tabular}{lc}
\hline Scoring Criteria & Score \\
\hline $\begin{array}{l}\text { Few, but standard, interfaces; few system elements; simple coupling } \\
\text { mechanisms between elements; simple element architecture orientation }\end{array}$ & 5 \\
\hline $\begin{array}{l}\text { Few non-standard interfaces, some standard interfaces; manageable } \\
\text { architecture; some non-standard coupling between system elements }\end{array}$ & 3 \\
\hline $\begin{array}{l}\text { Many non-standard interfaces; many separate system elements; } \\
\text { complex coupling mechanisms between system elements; unusual } \\
\text { element architecture orientation }\end{array}$ & 1 \\
\hline
\end{tabular}

A scoring system is defined for each of the different selection criteria. If within a criterion there are several different aspects, then sub criteria are used to fully define all the different aspects. These are combined to form a single score for the criterion, through either an arithmetic or weighted mean.

\subsection{Combining Analyses}

The results from the quantitative analysis are normalised against the maximum value, and the qualitative scores are normalised against the maximum value, 5 . A weighting for each of the criteria is decided by project stakeholders, as recommended by [7]. These weightings are multiplied by normalised scores from the quantitative and qualitative analyses to give a final score for each turbine solution. The scores can then be analysed and an appropriate solution chosen. In the following Sections, the method described above is shown through an example.

\section{Example of Pico-Hydro Turbine Selection Using Multi-Criteria Analysis}

The village of Bhanbhane in central Nepal has several low head sites for turbines. The heads at the sites vary from $0.5 \mathrm{~m}$ to $3.5 \mathrm{~m}$, the flow available at the sites also varies depending on the season and the location in the river. There are two different rivers that would supply the sites. The villagers would like to install the same turbine in all of the locations, making savings in bulk buying and allowing them to stockpile spares. At each turbine site, they do not require more than $1 \mathrm{~kW}$ of electric power, so allowing for inefficiencies in the system, such as drive and generator losses, the turbine should produce $1.3 \mathrm{~kW}$ of mechanical power. Bhanbhane is a rural village, and the sites lie several kilometres from the nearest road, so the units need to be portable, ideally able to be carried by villagers. Also, with the rural location and the distance from a road, cement is expensive and difficult to obtain, therefore the civil works should be minimised. The villagers intend to carry out on-site maintenance and servicing themselves, so the unit should be simple to maintain and have a modular design allowing faulty modules to be easily identified and replaced. Any faulty modules that cannot be repaired onsite are to be returned to the manufacturer or a service centre for repair. It is 
assumed that the generator output is $50 \mathrm{~Hz}$, with a direct interface to the distribution system. From this, the specification for the turbine is derived (Table 2), and the selection criteria developed (Table 3).

Table 2. Turbine specification

Power: $1.3 \mathrm{~kW}$

Head: Range from 0.5 to $3.5 \mathrm{~m}$

Portability: Able to be transported to locations with limited transport infrastructure

Reliability: High reliability for low maintenance operation

Output Frequency: $50 \mathrm{~Hz}$ output from generator

Maintenance: Maintenance and servicing carried out by unskilled labour

Flow rate: Large variation across the seasons

Modularity: Turbine in modules to allow for easy fault identification and module replacement

Civil works: Small civil works

Table 3. Selection criteria

Efficiency: Efficiency of the unit at rated flow/head and at part flow/part head

Power: Power of the unit must be $1.3 \mathrm{~kW}$

Portability: Minimised volume for easy transportation

Civil Works: Minimised civil works - concrete sparsely available in site locations

Modularity: Scope to incorporate modularity into the design for line replaceable units and to disassemble the unit for ease of portability

Maintenance \& The ease of maintaining and servicing the unit, especially with

Serviceability: unskilled labour.

Here, power and head are the known variables, with the efficiency and flow rate required from the quantitative analysis. The volume of the unit is estimated as a function of the flow rate and using existing designs and rules, for example [8]. The portability and power are dealt with by deriving a power density metric (rated power/volume) which provides the volume required to generate $1.3 \mathrm{~kW}$. This volume includes the penstock, turbine and casing. The power density and rated flow efficiency are thus treated by the quantitative analysis, whilst the part flow/part head efficiency, civil works, modularity and maintenance will be analysed qualitatively. The quantitative analysis designs a set of turbines for heads from $0.5 \mathrm{~m}$ to $3.5 \mathrm{~m}$ in $0.5 \mathrm{~m}$ steps. Power density is chosen to be the most important criterion, as if the unit is too large and unwieldy then the villagers will not be able to implement it in their chosen sites. The maintenance and serviceability and modularity in the design are considered less important, which is reflected in the weightings, shown in Table 4.

Table 4. Weighting scheme for example.

\begin{tabular}{cc}
\hline Selection Criteria & Weighting \\
\hline Power Density & 0.30 \\
Rated Flow Efficiency & 0.25 \\
Part Flow, Part Head Efficiency & 0.20 \\
Civil Works & 0.15 \\
Maintainability \& Serviceability & 0.05 \\
Scope for Modularity & 0.05 \\
\hline
\end{tabular}

The turbines assessed represent the four main different turbine types described in Section 2.2. Impulse and reaction turbines require a penstock, which is assumed to have a $5 \%$ head loss. 
The multiple jet turbines are assumed to have four jets which give it a volume and efficiency penalty. It is assumed that the turbine is connected to a generator that can produce $50 \mathrm{~Hz}$ as long as the rotational speed is between 200 and $3000 \mathrm{rpm}$ (commercially available generators). If the rotational speed is less than or greater than these limits, a gearbox is required to bring the speed within these limits and so gearbox efficiency is taken into account.

\section{Results}

The results from the quantitative analysis are shown in Fig. 2. The summary of the results from the combined analysis are shown in Fig. 3 and 4. 

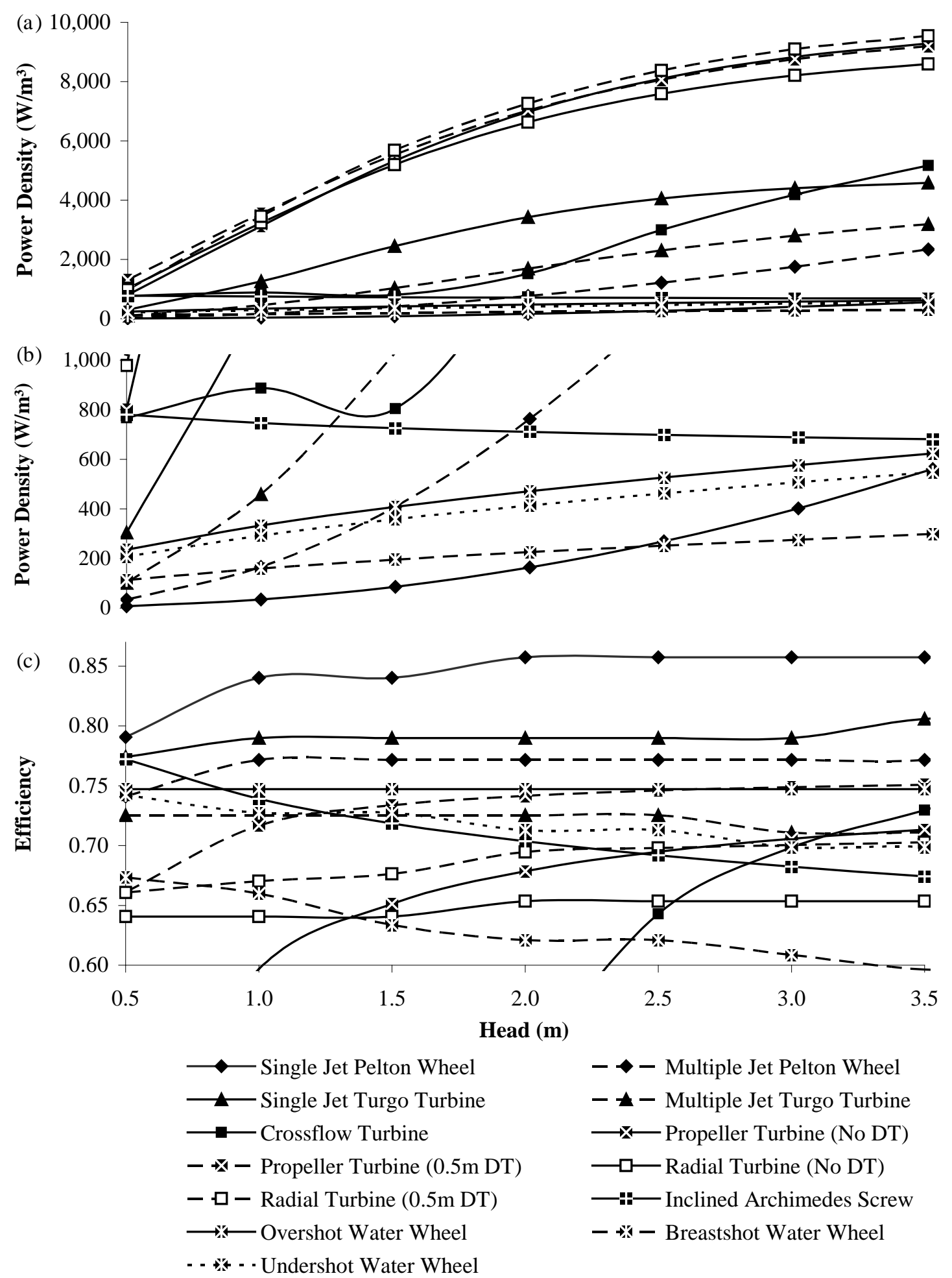

$$
\begin{aligned}
& -\bullet-\text { Multiple Jet Pelton Wheel } \\
& \text { - } \mathbf{-} \text { - Multiple Jet Turgo Turbine } \\
& \longrightarrow \longleftarrow \text { Propeller Turbine (No DT) } \\
& \longrightarrow \square-\text { Radial Turbine (No DT) } \\
& \text { - - Inclined Archimedes Screw } \\
& -\rightarrow \mathbb{*}-\text { Breastshot Water Wheel }
\end{aligned}
$$

Fig. 2. The output of the quantitative analysis: (a) power density (b) power density zoomed in at low power density (c) efficiency variation over the head range 0.5 to $3.5 \mathrm{~m}$, 'DT'=Draft Tube. 


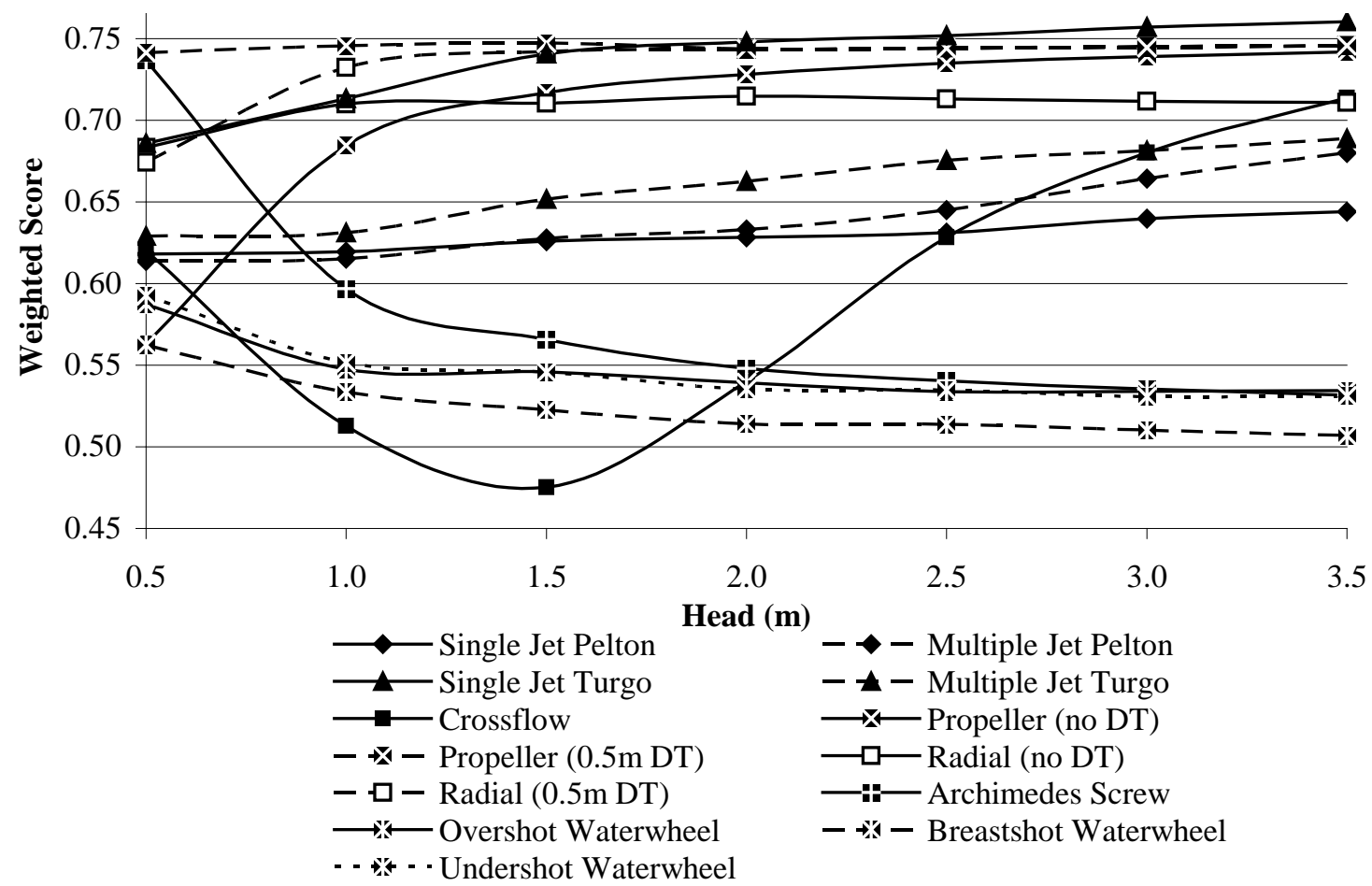

Fig. 3. The weighted scores for the 13 turbine choices over the head range 0.5 to $3.5 \mathrm{~m}$, 'DT'=Draft Tube.

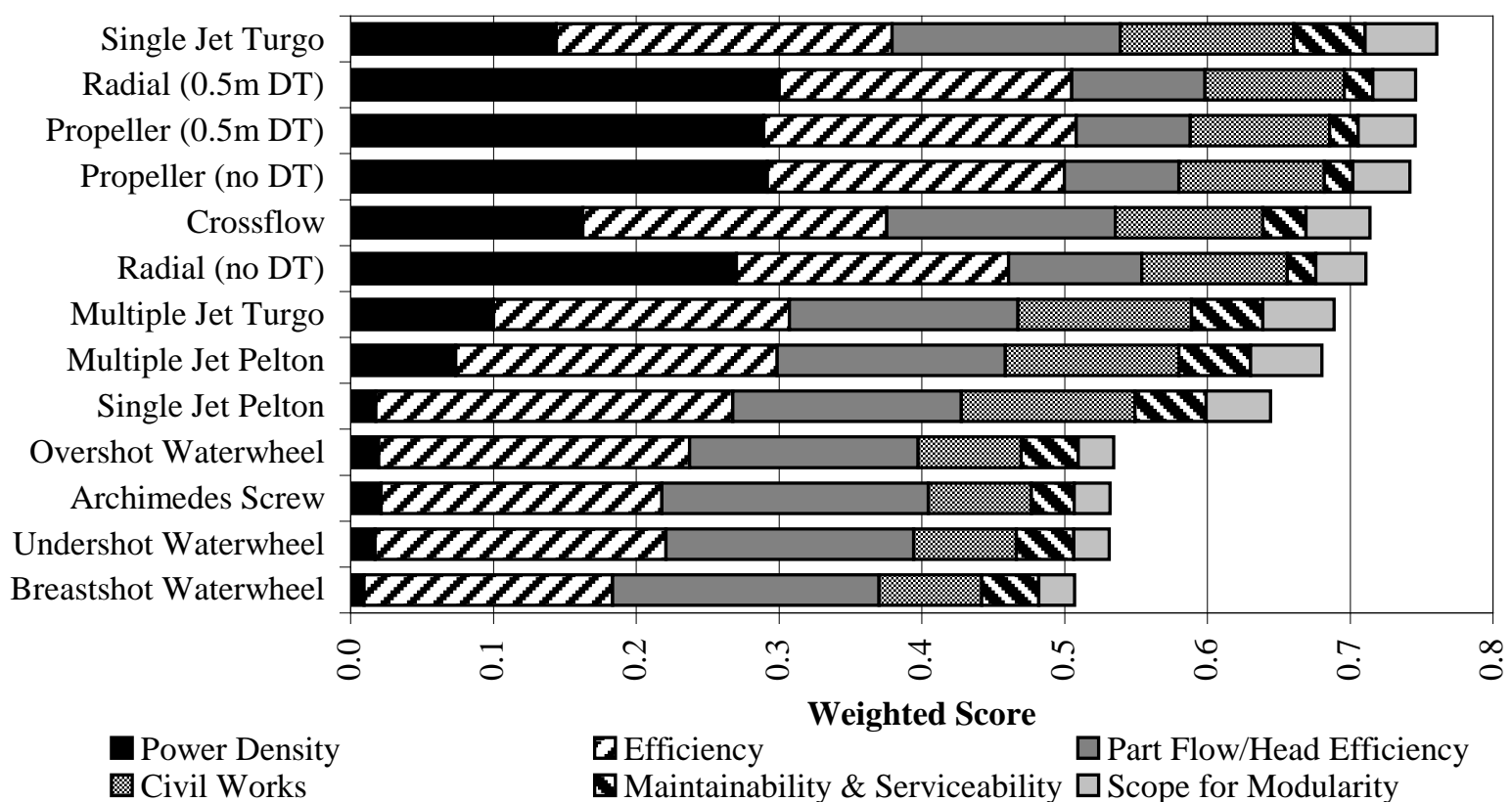

Fig. 4. The weighted score at $3.5 \mathrm{~m}$ head for the 13 turbine choices with the contributions from each of the different selection criteria, 'DT'=Draft Tube.

Using this selection method and the specification in Table 2, the propeller turbine with draft tube (DT) should be selected if the typical head is between 0.5 and $1.5 \mathrm{~m}$, and the single-jet Turgo turbine should be selected if the typical head is between 1.5 and $3.5 \mathrm{~m}$.

\section{Discussion}

Fig. 2 (a) shows that the reaction turbines have a superior power density. As the head increases, the power density of the impulse turbines and waterwheels improves, whilst that of 
the Archimedes Screw decreases. The conventional solution of adding multiple jets for Pelton and Turgo turbines at low heads is penalised in the power density, as the extra pipe work required to feed the jets takes up a large amount of volume. The efficiency of the single jet impulse turbines is superior to all the other turbines, as shown in Fig. 2 (c). As the head increases then the speed of the impulse turbine increases, so removing the need for a gearbox, increasing the overall efficiency of the turbine. Fig. 3 shows the variation in the weighted scores over the head range. This shows that a propeller turbine with a draft tube is the most suitable solution between 0.5 and $1.5 \mathrm{~m}$ typical head, with the single-jet Turgo turbine the best solution above $1.5 \mathrm{~m}$ typical head. The propeller and radial turbines with draft tubes have a similar weighted score to the single-jet Turgo turbine above $1.5 \mathrm{~m}$ head and therefore are viable choices for the specification. The reaction turbine result is expected, as many of the low head commercial turbine systems available are propeller turbines with draft tubes. The surprising result in this analysis is the Turgo turbine which is usually only used in medium to high heads - as indicated in the application range graph in Fig. 1, and stated in several literature resources such as [2]. However, as Harvey points out in [8], the Pelton turbine, and therefore the Turgo turbine, can be used in low heads if low speed and runner size do not pose problems. Using the calculations in the previous section, the runner diameter for a single-jet Turgo turbine generating $1.3 \mathrm{~kW}$ at $3.5 \mathrm{~m}$ head would be $435 \mathrm{~mm}$, which would therefore not pose a portability problem in rural areas.

\section{Conclusion}

This research is part of a project to develop a low head pico-hydro off-grid network. The turbine selection is the first phase of the project which will look at developing the network technology requirements. This paper has presented a method of selecting low head pico hydro turbines through a multi-criteria analysis, using the specification of the turbine to assess the turbine types through quantitative and qualitative analyses. Using this method, a propeller turbine with a draft tube or a single-jet Turgo turbine has been shown to be the best solution for a given low head, variable flow specification.

\section{Acknowledgements}

This research is funded by Renishaw plc, and supported by Engineers Without Borders, UK.

\section{References}

[1] B. Massey, Mechanics of Fluids, Stanley Thornes Ltd, $7^{\text {th }}$ Edition, 1998.

[2] O. Paish, Micro-hydropower: status and prospects, Proceedings of the Institution of Mechanical Engineers, Part A: Journal of Power and Energy, 216(1), 2002, pp.31-40.

[3] G. Muller and K. Kauppert, Old Watermills - Britain's new source of energy?, Proceedings of the ICE: Civil Engineering, 150, November 2002, pp.178-186.

[4] European Small Hydropower Association, A Layman's Guidebook on How to Develop a Small Hydro Site, $2^{\text {nd }}$ Edition, 1998.

[5] G. Muller and J. Senior, Simplified Theory of Archimedean Screws, Journal of Hydraulic Research, 47(5), 2009, pp.666-669.

[6] F. C. Lea, Hydraulics for Engineers and Engineering Students, Edward Arnold, 1945.

[7] S. Pugh, Total Design, Prentice Hall, $1^{\text {st }}$ Edition, 1991.

[8] A. Harvey et al, Micro-Hydro Design Manual, ITDG Publishing $1^{\text {st }}$ Edition, 1993. 